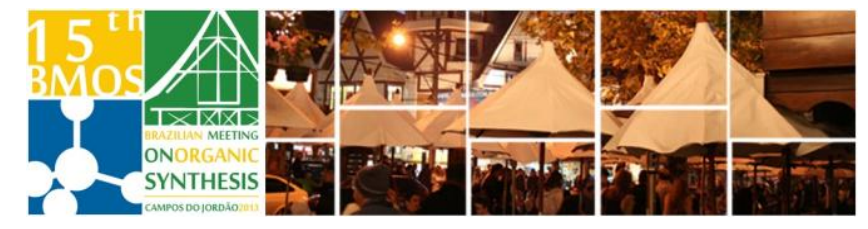

\title{
Sonochemistry to promote the synthesis of 5- arilydenethiazolidine-2,4-diones
}

\section{Bruna Bento Drawanz $^{1^{*}}$, Camila Ribeiro ${ }^{1}$, Hellen G. Masteloto ${ }^{1}$, Geonir M. Siqueira ${ }^{1}$ Wilson Cunico'}

\author{
${ }^{1}$ LaQuiABio- Laboratório de Química Aplicada à Bioativos, CCQFA, UFPel \\ *brunadrawanz@yahoo.com.br
}

Keywords: thiazolidine-2,4-diones; aldol condensation; sonochemistry

\section{INTRODUCTION}

There are many studies describing the biologic properties of 5-arylidene-2,4thiazolidinediones like: aldose reductase inhibitors, antibacterial, anti-cancer, antioxidant and antifungal. ${ }^{1}$ For this aldol condensation, the literature reports several methods such as: $\mathrm{KOH}$ or piperidine in reflux of ethanol or toluene, ${ }^{2}$ polyethene glycol (PEG-300) in reflux without base ${ }^{3}$. These conditions take some hours of reaction. Nowadays, several studies have been done looking for new methods that increase the speed of some reactions. The literature shows the emerging use of microwave irradiation to promote some synthesis, among them, the synthesis of 5-arylidene-2,4-thiazolidinediones between 10-30 minutes. ${ }^{4}$ In the same way, other good possibility is the use of sonochemistry once the ultrasound irradiation produces the cavitation effect that accelerates several synthetic reactions. ${ }^{5}$ So, the aim of this work was describe the capacity of ultrasound irradiation methodology to synthesis of 5arilydenethiazolidine-2,4-diones.

\section{RESULTS AND DISCUSSION}

All the compounds were previously on literature published by other methodologies, but the ultrasound irradiation by probe methodology never was related. So it was necessary to study the reaction conditions by ultrasound irradiation that was carried out in different bases: sodium acetate, triethylamine and potassium hydroxide. The best result was using the excess of potassium hydroxide for 20 min under sonication (as shown by GC). So, the 5-arilydenethiazolidine-2,4-diones 3a-p were synthesized from reaction of $1 \mathrm{mmol}$ of $2,4-$ thiazolidinedione 1, $1 \mathrm{mmol}$ of arenealdehyde $\mathbf{2 a - p}$ and $2 \mathrm{mmol}$ of potassium hydroxide in $10 \mathrm{~mL}$ of ethanol (Scheme 1). The reaction times were continuing monitored to all arenaldehydes and the final times are shows in Table 1. The pure products were obtained from moderated to good yields (Table 1). The products were confirmed by GC-MS analysis, by ${ }^{1} \mathrm{H}$ due mainly by the signal of vinilic hydrogen at 7.29-7.96 ppm and by ${ }^{13} \mathrm{C}$ NMR analysis that showed signals for all carbons.
Scheme 1. Synthesis of the compounds 3a-p.<smiles>O=C1CS[C+](=O)C1</smiles>

1<smiles>O=Cc1ccccc1</smiles>
$\underset{\text { ethanol } \quad))}{\stackrel{\mathrm{KOH}}{\longrightarrow}}$

2a-p

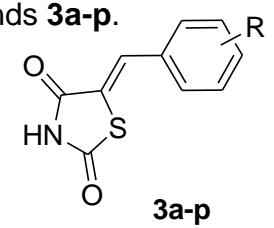

3a-p
Table 1. Yields and reaction time for the 3a-p compounds.

\begin{tabular}{|c|c|c|c|}
\hline & $\mathbf{R}$ & Time (min) & Yield (\%) \\
\hline $3 a$ & $2-\mathrm{OCH}_{3}$ & 15 & 51 \\
\hline $3 b$ & $3-\mathrm{OCH}_{3}$ & 15 & 65 \\
\hline $3 c$ & $4-\mathrm{OCH}_{3}$ & 20 & 34 \\
\hline $3 d$ & $3-\mathrm{Cl}$ & 15 & 81 \\
\hline $3 e$ & $4-\mathrm{Cl}$ & 15 & 72 \\
\hline $3 f$ & $2-F$ & 15 & 50 \\
\hline $3 g$ & $3-F$ & 15 & 62 \\
\hline $3 h$ & $4-\mathrm{F}$ & 10 & 54 \\
\hline $3 \mathbf{i}$ & $4-\mathrm{CH}_{3}$ & 15 & 40 \\
\hline $3 \mathbf{j}$ & $3-\mathrm{OH}$ & 15 & 25 \\
\hline $3 k$ & $3,4-\mathrm{OCH}_{3}$ & 15 & 30 \\
\hline 31 & $2,3-\mathrm{OCH}_{3}$ & 20 & 51 \\
\hline $3 m$ & $2,4-\mathrm{OCH}_{3}$ & 10 & 69 \\
\hline $3 n$ & $2,5-\mathrm{OCH}_{3}$ & 15 & 58 \\
\hline 30 & $2,6-\mathrm{Cl}$ & 15 & 79 \\
\hline $3 p$ & 2-Cl, 6-F & 10 & 80 \\
\hline
\end{tabular}

ayields of purified compounds by washing with hot solution mixture of hexane:ethyl acetate $(9: 1)$

\section{CONCLUSION}

In conclusion,

sixteen 5arilydenethiazolidine-2,4-diones were obtained by ultrasound irradiation. The present work shows another organic reaction promoted by ultrasound. These results inspiring the achievement of new synthetics studies through sonochemistry.

\section{ACKNOWLEDGEMENTS}

Thanks CAPES, FAPERGS, and UFPel

\section{REFERENCES}

1Jain, V. S.; Vora, D. K.; Ramaa, C. S. Bioorg. Med. Chem. 2013, 21, 1599.

${ }^{2}$ Bruno, G.; Costantino, L.; Curinga, C.; Maccari, R.; Monforte, F.; Nicolo, F.; Ottana, R.; Vigorita, M. G. Bioorg. Med. Chem. 2002, 10, 1077.

${ }^{3}$ Mahalle,S.R.; Netankar, P. D.; Bondge,S.P; Mane, R. A. Green. Chem. Lett. Rev. 2008, 1, 103.

${ }^{4}$ Kumar, B. R. P.; Soni, M.; Kumar, S. S.; Singh, K.; Patil, M.; Baig, R. B. N.; Adhikary, L. Eur. J. Med. Chem. 2011, 46, 835.

${ }^{5}$ Cravotto, G.; Cintas, P. Chem. Soc. Rev. 2006, 35, 180. 